\title{
Anaerobic Growth of Staphylococcus Species from Human Skin: Effects of Uracil and Pyruvate ${ }^{1}$
}

\author{
JAMES B. EVANS \\ Department of Microbiology, North Carolina State University, Raleigh, North Carolina 27607
}

\begin{abstract}
A collection of 178 strains of staphylococci from human skin, representing the three generally accepted species (Staphylococcus aureus, S. epidermidis, and S. saprophyticus) and seven recently proposed new species (S. simulans, S. cohnii, $S$. xylosus, S. warneri, S. capitis, S. haemolyticus, and S. hominis), was studied with regard to their requirements for uracil and pyruvate for anaerobic growth. S. saprophyticus and six of the proposed new species required both of these nutrients for good anaerobic growth and achieved essentially no growth when both were absent from the medium. $S$. simulans was unique in having no requirement for these nutrients for vigorous anaerobic growth. Only eight strains, six of $S$. cohnii and two of $S$. haemolyticus, gave no anaerobic growth in the medium with both uracil and pyruvate. Many strains of $S$. epidermidis and $S$. aureus grew well when both substances were absent but grew somewhat better when one or both were present. The taxonomic implications of this study provide some support for acceptance of several of the proposed new species.
\end{abstract}

The ability to grow anaerobically has been accepted as a major taxonomic criterion of the genus Staphylococcus (1). It has been accepted for many years that Staphylococcus aureus requires the addition of uracil and pyruvate for anaerobic growth in media that will support aerobic growth (4). Staphylococcus epidermidis was reported to require uracil, but not pyruvate, as an added nutrient for anaerobic growth (2). I have recently reported that anaerobic growth of these two species is greatly enhanced by these two nutrients but that many strains achieve moderate growth in their absence (J. B. Evans, J. Clin. Microbiol., in press). Most strains of Staphylococcus saprophyticus, however, had an absolute requirement for both uracil and pyruvate for anaerobic growth, and even then their growth was generally inferior to that of the other two species (Evans, in press).

A comprehensive taxonomic study of staphylococci on human skin has resulted in a more detailed description of these three species and of seven proposed new species in the genus Staphylococcus $(3,5)$. Through the generous cooperation of the authors of these published studies, a collection of 178 strains representing all 10 species of their proposed classification was made available for nutritional studies. The present report summarizes the relationship of uracil and pyruvate to the anaerobic growth of cultures of these strains.

\footnotetext{
1 Paper no. 4730 of the Journal Series of the North Carolina Agricultural Experiment Station, Raleigh, N.C.
}

\section{MATERIALS AND METHODS}

All strains included in this study were isolated from human skin, and a detailed study of their taxonomic characteristics and classification has been published $(3,5)$. The media and experimental procedures used were identical to those reported in a previous study (Evans, in press).

\section{RESULTS}

The results obtained with strains of the three established species (S. aureus, S. epidermidis, and $S$. saprophyticus) (Table 1) confirm and extend those in my previous report (Evans, in press). Strains of $S$. aureus are capable of weak to moderate growth in the basal medium, show a marked stimulation by either uracil or pyruvate, and grow best when both of these are added. Strains of $S$. epidermidis seem to fall into two categories: some that grow poorly in the basal medium, and a majority that grow very well in it. Both types achieve increased growth, however, when uracil and pyruvate are added, but exceptions are not unusual. None of the 15 strains of $S$. saprophyticus grew significantly in the basal medium; most strains were slightly stimulated by uracil but not by pyruvate; and all strains grew moderately well when both supplements were added.

The most striking results seemed to be with Staphylococcus simulans (Table 2). All 12 strains produced very heavy anaerobic growth in the basal medium with little or no additional growth as a result of addition of uracil and/or pyruvate. This is consistent with the results of Kloos and Schleifer (3), who reported that all 
TABLE 1. Uracil and pyruvate requirements for anaerobic growth of Staphylococcus aureus, Staphylococcus epidermidis, and Staphylococcus saprophyticus

\begin{tabular}{|c|c|c|c|c|c|c|c|c|c|c|c|c|c|c|}
\hline \multirow{2}{*}{$\begin{array}{l}S . \text { au- } \\
\text { reus } \\
\text { strains }\end{array}$} & \multicolumn{4}{|c|}{$\begin{array}{l}\text { Growth }{ }^{a} \text { in basal medium } \\
\text { with: }\end{array}$} & \multirow{2}{*}{$\begin{array}{l}\text { S. epider- } \\
\text { midis } \\
\text { strains }\end{array}$} & \multicolumn{4}{|c|}{$\begin{array}{c}\text { Growth }^{a} \text { in basal medium } \\
\text { with: }\end{array}$} & \multirow{2}{*}{$\begin{array}{l}\text { S. sapro- } \\
\text { phyticus } \\
\text { strains }\end{array}$} & \multicolumn{4}{|c|}{$\begin{array}{c}\text { Growth }{ }^{a} \text { in basal medium } \\
\text { with: }\end{array}$} \\
\hline & $\begin{array}{c}\text { No } \\
\text { addi- } \\
\text { tive }\end{array}$ & $\mathrm{U}$ & $\mathbf{P}$ & $\mathrm{U}_{\mathrm{P}}^{+}$ & & $\begin{array}{c}\text { No } \\
\text { addi- } \\
\text { tive }\end{array}$ & $\mathrm{U}$ & $\mathbf{P}$ & $\mathrm{U}_{\mathrm{P}}^{+}$ & & $\begin{array}{c}\text { No } \\
\text { addi- } \\
\text { tive }\end{array}$ & $\mathbf{U}$ & $\mathbf{P}$ & $\mathrm{U}_{\mathrm{P}}^{+}$ \\
\hline AW 151 & \begin{tabular}{|l|l|}
0.14 \\
\end{tabular} & 0.73 & 0.64 & 1.08 & MK 214 & 0.15 & 0.44 & 1.15 & 1.52 & KL 20 & 0.03 & 0.13 & 0.02 & 0.70 \\
\hline DM 171 & 0.10 & 0.61 & 0.17 & 0.93 & MK 206 & 0.15 & 0.07 & 0.72 & 1.22 & TW 111 & 0.01 & 0.07 & 0.03 & 0.82 \\
\hline MK 181 & 0.00 & 0.55 & 0.55 & 0.79 & MK 258 & 1.25 & 0.95 & 1.30 & 1.30 & SE 11 & 0.00 & 0.05 & 0.00 & 0.56 \\
\hline GH 38 & 0.74 & 0.90 & 1.00 & 1.35 & AW 269 & 0.35 & 0.57 & 1.45 & 1.52 & AW 163 & 0.03 & 0.12 & 0.06 & 0.83 \\
\hline KL 207 & 0.43 & 0.97 & 0.54 & 1.15 & DM 206 & 0.93 & 1.00 & 1.20 & 1.35 & DM 115 & 0.04 & 0.33 & 0.05 & 0.78 \\
\hline TW 55 & 0.15 & 0.72 & 0.66 & 1.12 & GH 37 & \begin{tabular}{|l|}
0.78 \\
\end{tabular} & 0.69 & 1.20 & 1.40 & KL 251 & 0.01 & 0.33 & 0.00 & 0.68 \\
\hline SM 171 & 0.29 & 0.52 & 0.64 & 0.67 & SM 225 & 0.83 & 0.40 & 1.30 & 1.45 & KL 150 & 0.00 & 0.06 & 0.00 & 0.56 \\
\hline PM 261 & 0.30 & 0.50 & 0.59 & 0.78 & RM 172 & 1.03 & 1.12 & 1.25 & 1.35 & KL 172 & 0.02 & 0.09 & 0.06 & 0.45 \\
\hline JL 68 & 0.46 & 0.75 & 0.62 & 1.02 & RM 351 & 0.18 & 0.25 & 0.78 & 0.80 & DM 66 & 0.01 & 0.16 & 0.01 & 0.83 \\
\hline KH 82 & 0.41 & 0.83 & 0.88 & 1.08 & JRM 1 & 0.81 & 1.30 & 0.66 & 1.45 & RM 454 & 0.05 & 0.30 & 0.02 & 0.83 \\
\hline LK 70 & 0.09 & 0.56 & 0.61 & 0.77 & MCS 21 & 0.77 & 0.48 & 1.45 & 1.50 & GH 196 & 0.06 & 0.10 & 0.04 & 0.83 \\
\hline MAW 306 & 0.32 & 0.78 & 0.77 & 1.02 & RK 13 & 0.16 & 0.50 & 0.67 & 1.35 & KL 122 & 0.00 & 0.08 & 0.01 & 0.19 \\
\hline SL 226 & \begin{tabular}{|l|}
0.48 \\
\end{tabular} & 0.84 & 0.63 & 1.15 & LK 69 & 0.35 & 0.64 & 1.70 & 1.85 & SM 118 & 0.00 & 0.08 & 0.01 & 0.80 \\
\hline KES D1 & 0.49 & 0.78 & 0.85 & 0.87 & KH 141 & 0.55 & 1.12 & 1.60 & 1.65 & SM 295 & 0.00 & 0.00 & 0.05 & 0.31 \\
\hline DHS D5 & 0.51 & 0.78 & 0.80 & 1.13 & PM 340 & 0.66 & 0.67 & 1.45 & 1.60 & JRM 27 & 0.01 & 0.01 & 0.00 & 0.81 \\
\hline DPS D1 & 0.26 & 0.90 & 0.92 & 1.13 & WK 5 & 1.10 & 1.50 & 1.85 & 1.85 & & & & & \\
\hline SK D3 & $\mid 0.47$ & 0.82 & 0.90 & 0.92 & TW 257 & 0.21 & 0.23 & 0.77 & 0.56 & & & & & \\
\hline MCS D2 & 0.37 & 0.80 & 0.80 & 1.10 & JL 120 & 0.68 & 0.80 & 1.08 & 1.20 & & & & & \\
\hline DW 143 & 0.38 & 0.74 & 0.57 & 1.05 & DM 134 & $\mid 0.88$ & 1.10 & 1.35 & 1.40 & & & & & \\
\hline TM 122 & 0.19 & 0.54 & 0.56 & 0.83 & EK 27 & 0.93 & 1.20 & 1.35 & 1.40 & & & & & \\
\hline
\end{tabular}

${ }^{a}$ Growth is expressed as optical density at $600 \mathrm{~nm}$ after anaerobic incubation at $35 \mathrm{C}$ for 3 days. Abbreviations: $\mathrm{P}$, pyruvate; $\mathrm{U}$, uracil.

strains of $S$. simulans produced uniformly dense anaerobic growth in thioglycolate semisolid medium, as do most strains of $S$. aureus and $S$. epidermidis. The uniformity of results with these 12 strains was particularly striking and tends to support their separation into a distinct taxonomic entity.

The strains identified as belonging to Staphylococcus cohnii seem to fall into three groups (Table 2). Six of the 20 strains failed to grow even when both uracil and pyruvate were added to the basal medium. The other 14 strains divided into the two types of response that were shown by strains of S. saprophyticus. Six strains indicated a moderate response to uracil alone, none were stimulated by pyruvate alone, and all but one of these strains showed a moderate to strong pyruvate effect when both supplements were added.

Staphylococcus xylosus (Table 2) gave a pattern of results that was very similar to that of $S$. saprophyticus. It produced little or no growth in the basal medium, a considerable response to uracil, and no response to pyruvate except when it was added with uracil. The uracil effect was generally greater than it was with S. saprophyticus or S. cohnii.

All of the strains of Staphylococcus warneri (Table 2) produced little or no growth in the basal medium. Most strains were markedly stimulated by either uracil or pyruvate individually, much like $S$. aureus, and grew very well when both were added. The remaining strains were similar to the two types of $S$. saprophyticus in that they were not stimulated by pyruvate alone, but some showed a uracil effect.

The remaining three species (Table 3 ) seemed to have a high degree of similarity to each other and had two primary patterns of response. The majority of the strains of Staphylococcus capitis and Staphylococcus haemolyticus, and a few strains of Staphylococcus hominis, produced little or no growth in the basal medium when either uracil or pyruvate was added separately but produced moderate growth when both were added. The remaining strains of these three species showed a weak to moderate growth response to pyruvate alone but not to uracil alone. With pyruvate alone, several strains of $S$. hominis grew as well as or better than when pyruvate and uracil were both present. S. capitis strains generally grew better in the medium with both pyruvate and uracil than did strains of the other two species.

Of the 178 strains studied, only eight failed to achieve at least some anaerobic growth when both pyruvate and uracil were added. Six of these were $S$. cohnii strains and two were $S$. 
TABLE 2. Uracil and pyruvate requirements for anaerobic growth of Staphylococcus simulans, Staphylococcus xylosus, Staphylococcus cohnii, and Staphylococcus warneri

\begin{tabular}{|c|c|c|c|c|c|c|c|c|c|}
\hline \multirow{2}{*}{$\begin{array}{l}\text { S. simulans } \\
\text { strains }\end{array}$} & \multicolumn{4}{|c|}{ Growth $^{a}$ in basal medium with: } & \multirow{2}{*}{$\begin{array}{l}\text { S. xylosus } \\
\text { strains }\end{array}$} & \multicolumn{4}{|c|}{ Growth ${ }^{a}$ in basal medium with: } \\
\hline & $\begin{array}{l}\text { No addi- } \\
\text { tive }\end{array}$ & $\mathrm{U}$ & $\mathbf{P}$ & $\mathbf{U}+\mathbf{P}$ & & $\begin{array}{l}\text { No addi- } \\
\text { tive }\end{array}$ & $\mathrm{U}$ & $\mathbf{P}$ & $\mathbf{U}+\mathbf{P}$ \\
\hline ATCC 27848 & 0.97 & 0.98 & 0.87 & 0.88 & DSM 20266 & 0.02 & 0.01 & 0.01 & 0.77 \\
\hline ATCC 27849 & 0.91 & 0.96 & 0.98 & 1.08 & DSM 20267 & 0.03 & 0.15 & 0.02 & 0.18 \\
\hline ATCC 27850 & 1.10 & 1.08 & 1.25 & 1.20 & DSM 20268 & 0.06 & 0.23 & 0.05 & 0.69 \\
\hline AW 232 & 1.05 & 1.05 & 1.10 & 1.15 & DM 37 & 0.05 & 0.40 & 0.05 & 0.65 \\
\hline SM 128 & 1.15 & 1.20 & 1.15 & 1.20 & DM 30 & 0.02 & 0.09 & 0.02 & 0.52 \\
\hline SM 81 & 1.15 & 1.10 & 1.00 & 1.20 & SM 212 & 0.07 & 0.42 & 0.05 & 0.82 \\
\hline KL 299 & 1.08 & 1.15 & 1.30 & 1.25 & SM 247 & 0.03 & 0.55 & 0.03 & 0.62 \\
\hline KL 104 & 1.20 & 1.20 & 1.25 & 1.30 & TW 41 & 0.03 & 0.07 & 0.03 & 0.28 \\
\hline MAW 222 & 1.30 & 1.25 & 1.40 & 1.40 & TW 83 & 0.01 & 0.34 & 0.01 & 0.53 \\
\hline $\mathrm{HK} 12$ & 1.45 & 1.50 & 1.05 & 1.50 & TW 54 & 0.00 & 0.36 & 0.03 & 0.26 \\
\hline DW 196 & 1.07 & 1.03 & 1.15 & 1.20 & AW 124 & 0.06 & 0.32 & 0.03 & 0.74 \\
\hline \multirow[t]{8}{*}{ CE 13} & 1.12 & 1.15 & 1.30 & 1.30 & KH 168 & 0.08 & 0.51 & 0.03 & 0.52 \\
\hline & & & & & GH 30 & 0.16 & 0.54 & 0.08 & 0.82 \\
\hline & & & & & SL 114 & 0.15 & 0.43 & 0.06 & 0.73 \\
\hline & & & & & SE 4 & 0.13 & 0.18 & 0.07 & 0.81 \\
\hline & & & & & DM 172 & 0.08 & 0.57 & 0.05 & 0.54 \\
\hline & & & & & SM 159 & 0.07 & 0.51 & 0.01 & 0.75 \\
\hline & & & & & KL 236 & 0.09 & 0.49 & 0.05 & 0.78 \\
\hline & & & & & KL 117 & 0.02 & 0.43 & 0.02 & 0.81 \\
\hline
\end{tabular}

\begin{tabular}{|c|c|c|c|c|c|c|c|c|c|}
\hline \multirow{2}{*}{$\begin{array}{l}\text { S. cohnii strains } \\
\text { DSM } 20260\end{array}$} & \multicolumn{9}{|c|}{$\begin{array}{l}\text { S. warneri } \\
\text { strains }\end{array}$} \\
\hline & 0.01 & 0.02 & 0.00 & 0.08 & ATCC 27836 & 0.04 & 0.49 & 0.47 & 0.73 \\
\hline DSM 20261 & 0.00 & 0.00 & 0.00 & 0.00 & ATCC 27837 & 0.01 & 0.03 & 0.03 & 0.70 \\
\hline DSM 20262 & 0.04 & 0.01 & 0.05 & 0.50 & ATCC 27838 & 0.02 & 0.54 & 0.06 & 0.74 \\
\hline DM 224 & 0.02 & 0.00 & 0.00 & 0.00 & ATCC 27839 & 0.06 & 0.60 & 0.54 & 0.94 \\
\hline DM 272 & 0.00 & 0.00 & 0.00 & 0.00 & WK 193 & 0.03 & 0.72 & 0.20 & 1.05 \\
\hline DM 154 & 0.03 & 0.39 & 0.05 & 0.43 & MK 222 & 0.01 & 0.16 & 0.01 & 0.17 \\
\hline MK 247 & 0.02 & 0.21 & 0.05 & 0.53 & SM 219 & 0.03 & 0.02 & 0.04 & 0.37 \\
\hline RM 429 & 0.00 & 0.00 & 0.00 & 0.40 & SM 251 & 0.00 & 0.67 & 0.25 & 0.67 \\
\hline CK 27 & 0.00 & 0.17 & 0.06 & 0.47 & TW 98 & 0.01 & 0.37 & 0.27 & 0.90 \\
\hline LK 478 & 0.02 & 0.01 & 0.08 & 0.29 & JL 289 & 0.07 & 0.60 & 1.05 & 1.00 \\
\hline KH 201 & 0.02 & 0.02 & 0.02 & 0.09 & KH 127 & 0.05 & 0.53 & 0.58 & 1.00 \\
\hline RM 10 & 0.01 & 0.01 & 0.06 & 1.10 & MAW 314 & 0.08 & 0.54 & 0.70 & 1.12 \\
\hline PM 244 & 0.02 & 0.00 & 0.03 & 0.91 & JM 25 & 0.02 & 0.18 & 0.08 & 0.40 \\
\hline CM 89 & 0.06 & 0.27 & 0.05 & 0.73 & KL 105 & 0.12 & 0.33 & 0.49 & 1.00 \\
\hline DBM 388 & 0.03 & 0.51 & 0.09 & 0.87 & KL 195 & 0.08 & 0.50 & 0.35 & 0.95 \\
\hline DBM 247 & 0.00 & 0.00 & 0.00 & 0.47 & $\operatorname{MCS} 4$ & 0.01 & 0.04 & 0.10 & 0.90 \\
\hline JL 143 & 0.05 & 0.28 & 0.04 & 0.82 & & & & & \\
\hline JL 321 & 0.00 & 0.00 & 0.00 & 0.77 & & & & & \\
\hline JRM 24 & 0.00 & 0.00 & 0.01 & 0.39 & & & & & \\
\hline BB 3 & 0.00 & 0.00 & 0.00 & 0.04 & & & & & \\
\hline
\end{tabular}

${ }^{a}$ Growth is expressed as optical density at $600 \mathrm{~nm}$ after anaerobic incubation at $35 \mathrm{C}$ for 3 days. Abbreviations: $\mathrm{P}$, pyruvate; $\mathrm{U}$, uracil.

haemolyticus. Several other strains of these species grew poorly as did many strains of $S$. hominis and a few of $S$. xylosus.

\section{DISCUSSION}

The different types of growth-response patterns of staphylococci observed in these studies correlated quite well with the recently proposed speciation of these organisms (Table 4). The ability to achieve moderate to good growth in the basal medium is confined to, and generally characteristic of, $S$. aureus, $S$. epidermidis, and $S$. simulans. All strains of $S$. aureus and all but three strains of $S$. epidermidis showed considerable additional growth, however, when uracil and pyruvate were added. $S$. simulans characteristically gave heavy growth in the basal medium and little or no additional 
TABLE 3. Uracil and pyruvate requirements for anaerobic growth of Staphylococcus capitis, Staphylococcus haemolyticus, and Staphylococcus hominis

\begin{tabular}{|c|c|c|c|c|c|c|c|c|c|c|c|c|c|c|}
\hline \multirow{2}{*}{$\begin{array}{l}\text { S. capitis } \\
\text { strains }\end{array}$} & \multicolumn{4}{|c|}{$\begin{array}{c}\text { Growth }^{a} \text { in basal medium } \\
\text { with: }\end{array}$} & \multirow{2}{*}{$\begin{array}{l}\text { S. haemo- } \\
\text { lyticus } \\
\text { strains }\end{array}$} & \multicolumn{4}{|c|}{$\begin{array}{c}\text { Growth }^{a} \text { in basal medium } \\
\text { with: }\end{array}$} & \multirow{2}{*}{$\begin{array}{l}\text { S. hom- } \\
\text { inis } \\
\text { strains }\end{array}$} & \multicolumn{4}{|c|}{$\begin{array}{c}\text { Growth }^{a} \text { in basal medium } \\
\text { with: }\end{array}$} \\
\hline & $\begin{array}{c}\text { No } \\
\text { addi- } \\
\text { tive }\end{array}$ & $\mathrm{U}$ & $\mathbf{P}$ & $\begin{array}{c}\mathrm{U}_{\mathrm{P}}^{+} \\
\end{array}$ & & $\begin{array}{l}\text { No } \\
\text { addi- } \\
\text { tive }\end{array}$ & $\mathrm{U}$ & $P$ & $\mathrm{U}_{\mathrm{P}}^{+}$ & & $\begin{array}{c}\text { No } \\
\text { addi- } \\
\text { tive }\end{array}$ & $\mathrm{U}$ & $P$ & $\mathbf{U}_{\mathbf{P}}^{+}$ \\
\hline $\begin{array}{l}27840^{b} \\
27841^{b} \\
27842^{b} \\
27843^{b} \\
\text { RM } 390 \\
\text { GS } 14 \\
\text { KES } 14 \\
\text { CK 17 } \\
\text { RK } 23 \\
\text { KH } 220 \\
\text { PM } 378 \\
\text { WK 445 } \\
\text { DBM 213 } \\
\text { EK 11 } \\
\text { HM 11 } \\
\text { BS 2 } \\
\text { CE 2 } \\
\text { SK } 13\end{array}$ & \begin{tabular}{|l|}
0.04 \\
0.02 \\
0.01 \\
0.03 \\
0.03 \\
0.02 \\
0.00 \\
0.00 \\
0.00 \\
0.02 \\
0.02 \\
0.01 \\
0.05 \\
0.05 \\
0.03 \\
0.02 \\
0.01 \\
0.00
\end{tabular} & $\begin{array}{l}0.01 \\
0.03 \\
0.02 \\
0.02 \\
0.08 \\
0.03 \\
0.00 \\
0.00 \\
0.00 \\
0.01 \\
0.03 \\
0.05 \\
0.09 \\
0.05 \\
0.02 \\
0.03 \\
0.03 \\
0.00\end{array}$ & $\begin{array}{l}0.11 \\
0.12 \\
0.15 \\
0.08 \\
0.05 \\
0.15 \\
0.20 \\
0.07 \\
0.06 \\
0.06 \\
0.07 \\
0.09 \\
0.10 \\
0.32 \\
0.06 \\
0.25 \\
0.01 \\
0.02\end{array}$ & $\begin{array}{l}0.56 \\
0.54 \\
0.56 \\
0.82 \\
0.81 \\
0.56 \\
0.95 \\
0.53 \\
0.74 \\
1.10 \\
0.84 \\
0.85 \\
0.88 \\
1.20 \\
0.98 \\
1.05 \\
0.68 \\
0.68\end{array}$ & $\begin{array}{l}20263^{c} \\
20264^{c} \\
20265^{c} \\
\text { SM 102 } \\
\text { KL 109 } \\
\text { MK 67 } \\
\text { KL 35 } \\
\text { KL 194 } \\
\text { GH 59 } \\
\text { GH 107 } \\
\text { MK 50 } \\
\text { AW } 263 \\
\text { MK } 310 \\
\text { AW 174 } \\
\text { DM } 32 \\
\text { DM 70 } \\
\text { SM 254 } \\
\text { RM 357 } \\
\text { MK } 104 \\
\text { AW } 146 \\
\text { SM 74 } \\
\text { DM } 293\end{array}$ & \begin{tabular}{|l|}
0.03 \\
0.01 \\
0.00 \\
0.00 \\
0.01 \\
0.01 \\
0.00 \\
0.03 \\
0.01 \\
0.01 \\
0.00 \\
0.01 \\
0.00 \\
0.05 \\
0.05 \\
0.05 \\
0.10 \\
0.00 \\
0.00 \\
0.00 \\
0.02 \\
0.00
\end{tabular} & $\begin{array}{l}0.01 \\
0.01 \\
0.00 \\
0.00 \\
0.05 \\
0.02 \\
0.00 \\
0.00 \\
0.00 \\
0.00 \\
0.00 \\
0.07 \\
0.00 \\
0.02 \\
0.00 \\
0.01 \\
0.15 \\
0.00 \\
0.00 \\
0.00 \\
0.00 \\
0.00\end{array}$ & $\begin{array}{l}0.05 \\
0.07 \\
0.03 \\
0.02 \\
0.02 \\
0.02 \\
0.12 \\
0.07 \\
0.00 \\
0.01 \\
0.16 \\
0.12 \\
0.00 \\
0.23 \\
0.06 \\
0.53 \\
0.47 \\
0.16 \\
0.01 \\
0.00 \\
0.00 \\
0.01\end{array}$ & $\begin{array}{l}0.38 \\
0.37 \\
0.09 \\
0.37 \\
0.37 \\
0.22 \\
0.25 \\
0.32 \\
0.29 \\
0.23 \\
0.62 \\
0.61 \\
0.30 \\
0.42 \\
0.14 \\
0.21 \\
0.68 \\
0.27 \\
0.36 \\
0.29 \\
0.19 \\
0.02\end{array}$ & $\begin{array}{l}27845^{b} \\
27846^{b} \\
27847^{b} \\
\text { WK 52 } \\
\text { SM 67 } \\
\text { JL } 248 \\
\text { TW 52 } \\
\text { TW } 139 \\
\text { KH } 211 \\
\text { AW } 178 \\
\text { MCS } 13 \\
\text { GS } 16 \\
\text { DGS } 13 \\
\text { BS } 14 \\
\text { LK 47 } \\
\text { MK } 314\end{array}$ & $\begin{array}{l}0.03 \\
0.03 \\
0.03 \\
0.00 \\
0.00 \\
0.04 \\
0.00 \\
0.00 \\
0.00 \\
0.00 \\
0.06 \\
0.07 \\
0.05 \\
0.00 \\
0.03 \\
0.02\end{array}$ & $\begin{array}{l}0.00 \\
0.03 \\
0.04 \\
0.01 \\
0.00 \\
0.00 \\
0.00 \\
0.00 \\
0.00 \\
0.01 \\
0.04 \\
0.04 \\
0.02 \\
0.00 \\
0.02 \\
0.03\end{array}$ & $\begin{array}{l}0.27 \\
0.30 \\
0.22 \\
0.16 \\
0.16 \\
0.45 \\
0.17 \\
0.03 \\
0.41 \\
0.21 \\
0.49 \\
0.61 \\
0.42 \\
0.00 \\
0.10 \\
0.05\end{array}$ & $\begin{array}{l}0.40 \\
0.38 \\
0.40 \\
0.27 \\
0.59 \\
0.24 \\
0.37 \\
0.38 \\
0.34 \\
0.20 \\
0.29 \\
0.61 \\
0.53 \\
0.37 \\
0.23 \\
0.16\end{array}$ \\
\hline
\end{tabular}

${ }^{a}$ Growth is expressed as optical density at $600 \mathrm{~nm}$ after anaerobic incubation at $35 \mathrm{C}$ for 3 days. Abbreviations: $\mathrm{P}$, pyruvate; $\mathrm{U}$, uracil.

${ }^{b}$ American Type Culture Collection number.

c Deutsche Sammlung für Mikroorganismen number.

TABLE 4. Patterns of anaerobic growth response of Staphylococcus species to uracil and pyruvate ${ }^{a}$

\begin{tabular}{|c|c|c|c|c|c|c|}
\hline \multirow{3}{*}{ Staphylococcus species } & \multicolumn{6}{|c|}{ No. of strains which: } \\
\hline & \multicolumn{2}{|c|}{ Require: } & \multicolumn{3}{|c|}{ Are stimulated in growth by: ${ }^{b}$} & \multirow{2}{*}{$\begin{array}{l}\text { Yield no } \\
\text { growth in } \\
\text { basal me } \\
\text { dium }\end{array}$} \\
\hline & $\begin{array}{c}\text { Neither } U \\
\text { nor } P\end{array}$ & $\mathbf{U}+\mathbf{P}$ & $\mathrm{U}$ & $\mathbf{P}$ & $\mathrm{U}$ or $\mathrm{P}$ & \\
\hline S. aureus ${ }^{c}$ & 0 & 0 & 1 & 0 & 19 & 0 \\
\hline S. epidermidis ${ }^{c}$ & 3 & 0 & 0 & 7 & 10 & 0 \\
\hline S. simulans ${ }^{c}$ & 12 & 0 & 0 & 0 & 0 & 0 \\
\hline S. saprophyticus & 0 & 8 & 7 & 0 & 0 & 0 \\
\hline S. cohnii & 0 & 8 & 6 & 0 & 0 & 6 \\
\hline S. xylosus & 0 & 3 & 16 & $\mathbf{0}$ & 0 & 0 \\
\hline S. warneri & 0 & 3 & 3 & 0 & 10 & 0 \\
\hline S. capitis & 0 & 11 & 0 & 7 & 0 & 0 \\
\hline S. haemolyticus & 0 & 13 & 0 & 7 & 0 & 2 \\
\hline S. hominis & $\mathbf{0}$ & 3 & 0 & 13 & $\mathbf{0}$ & 0 \\
\hline
\end{tabular}

a Abbreviations: $\mathrm{P}$, pyruvate; U, uracil.

${ }^{b}$ Growth stimulated by U refers to cultures that gave increased growth when uracil alone was added, but not when pyruvate alone was added, even though much better growth was usually achieved when both were added together. Growth stimulated by $P$ refers to cultures similarly affected by pyruvate alone. Growth stimulated by $U$ or $P$ refers to cultures stimulated when uracil was added alone and also when pyruvate was added alone.

c Most cultures of $S$. aureus and $S$. epidermidis, and all cultures of $S$. simulans, grew well in the basal medium. All other cultures gave little or no growth in the basal medium. 
growth as a result of added uracil and pyruvate.

All strains of the other seven species produced little or no growth in the basal medium, and, except for six strains of $S$. cohnii and two strains of $S$. haemolyticus, all gave moderate to good growth in the medium with both uracil and pyruvate. As shown in Table 4, the remaining strains of these seven species may be separated into four types according to their response to uracil or pyruvate. The most common type (49 strains) shows essentially no growth response to uracil or pyruvate individually but must have both of these for growth. Strains of all seven species fall into this type. Most of the other strains show a slight growth response to uracil (32 strains) or pyruvate (27 strains) individually. Generally, this growth response is so weak that these strains really differ very little from the type that requires both. However, it is interesting that the response to uracil is found only in strains of $S$. saprophyticus, $S$. cohnii, $S$. xylosus, and S. warneri, and the response to pyruvate is found only in strains of $S$. capitis, $S$. haemolyticus, and $\boldsymbol{S}$. hominis.

Physiological similarities between $S$. saprophyticus, S. cohnii, and S. xylosus are shown in the data of Kloos and Scheifer $(3,5)$ in novobiocin resistance, peptidoglycan composition, lower maximum and minimum growth temperatures, and cell arrangement. Similarities between S. capitis, S. haemolyticus, and S. hominis are shown in level of lysostaphin resistance, novobiocin sensitivity, and mucopeptide composition. Some separation between species within these two groups is suggested by the magnitude of the growth response of $S$. xylosus to uracil and of $S$. capitis to uracil and pyruvate together.

The six strains of $S$. cohnii that were stimulated by uracil alone are the same strains that produced only 50 to $60 \%$ L-lactic acid in the study of Schleifer and Kloos (5). There were no other apparent correlations noted between the present nutritional studies and the extensive studies describing these species $(3,5)$.

$S$. warneri is the only species of these seven that gave a relatively strong growth response to pyruvate or uracil individually. Their response was like that of those strains of $S$. aureus that gave little growth in the basal medium.

Thus, of the seven recently proposed new species, the present study adds support to the taxonomic uniqueness of $S$. simulans and $S$. warneri and tends to separate the other five species into two groups. However, it is of limited help in determining whether or not these two groups deserve separation at the species or subspecies level.

\section{ACKNOWLEDGMENTS}

This investigation was supported by Public Health Service Biomedical Sciences Support Grant no. RR-07071.

Particular gratitude is due to W. E. Kloos, who provided the cultures used in this study.

\section{REPRINT REQUESTS}

Address reprint requests to: Dr. James B. Evans, Dept. of Microbiology, North Carolina State Univ., Raleigh, N.C. 26707 .

\section{LITERATURE CITED}

1. Baird-Parker, A. C. 1974. Staphylococcus, p. 483-489. In R. E. Buchanan and N. E. Gibbons (ed.), Bergey's manual of determinative bacteriology, 8th ed. The Williams \& Wilkins Co., Baltimore.

2. Jones, D., R. H. Deibel, and C. F. Niven, Jr. 1963. Identity of Staphylococcus epidermidis. J. Bacteriol. 85:62-67.

3. Kloos, W. E., and K. H. Schleifer. 1975. Isolation and characterization of staphylococci from human skin. II. Description of four new species: Staphylococcus warneri, Staphylococcus capitis, Staphylococcus hominis, and Staphylococcus simulans. Int. J. Syst. Bacteriol. 25:62-79.

4. Richardson, G. M. 1936. The nutrition of Staphylococcus aureus. Necessity for uracil in anaerobic growth. Biochem. J. 30:2184-2190.

5. Schleifer, K. H., and W. E. Kloos. 1975. Isolation and characterization of staphylococci from human skin. I. Amended description of Staphylococcus epidermidis and Staphylococcus saprophyticus and descriptions of three new species:Staphylococcus cohnii, Staphylococcus haemolyticus, and Staphylococcus xylosus. Int. J. Syst. Bacteriol. 25:50-61. 